\title{
The role of the form master's personality in the formation of the psychological climate of the school team
}

\author{
A.V. Speranskaya ${ }^{1 *}$, S.A. Prokopyeva ${ }^{2}$, and T.V. Kornilova ${ }^{3}$ \\ ${ }^{1}$ The Vologda Institute of Law and Economics of the Federal Penal Service of Russia, Vologda, \\ Russia \\ ${ }^{2}$ The Vologda Institute of Law and Economics of the Federal Penal Service of Russia, Vologda, \\ Russia \\ ${ }^{3}$ The Vologda Institute of Law and Economics of the Federal Penal Service of Russia, Vologda, \\ Russia
}

\begin{abstract}
The article shows the importance of form master's personality for the formation of the psychological climate in the classroom. The ability to form a favorable psychological climate in a supervised classroom by employing personality traits is regarded to be a high level of professionalism of a modern form master.
\end{abstract}

\section{A problem statement}

The school represents the most powerful institute of socialization in the life of every child during 9-11 years. School is the place where a growing child comprehends ground rules of life in groups, adult interaction. The child depends to some extent on adults in terms of the success of his or her education and the formation of status within a class. The child's attitude to his or her class and form master, the degree of psychological comfort during the stay in the classroom is important. This is especially acute in adolescence.

It's worth mentioning that there is a huge amount of research on adolescence in psychology. But most often, the child-parent relationships of a teenager, interpersonal peer relationships, and character accentuations come to the attention of researchers. Scientists focus on school motivation and professional choice while studying the learning process of teenagers. Much less attention is paid to the school community, its characteristics, and the study of factors that affect the school community.

The form master is the central socializing figure in the school. Moreover, he or she acts as a class teacher, not only as a subject teacher. The socio-psychological analysis of the form master's activity is poorly presented in scientific sources, although form masters themselves often have certain difficulties in working with the class.

Analysis of the content of professional activity allows to state that almost everything that concerns students is the responsibility of the form master, including their health, the

*Corresponding author: ipcs-profped@yandex.ru 
level of success in mastering the school curriculum, relationships between classmates, relationships with form masters and parents.

The form master organizes the activities of the school team, which consists of peers and is relatively independent of the influence of significant adults. This school team is also the most important institution of socialization of the individual [1].

The psychological climate in the school classroom plays an important role in the formation of productivity of children's studies and in actualization of their personal qualities (best or worst).

The above-mentioned role of the psychological climate in the development of a teenager's personality shows the necessity of investigating such a substantial factor that affects the formation of the psychological climate as the personality of the form master.

\subsection{The objective of the work}

Such researchers as Belkina V.N., Karpov A.V., Revyakina I.I. [2], Belkin A.S. [3], Praslova G. [4], Merzlyakova D.R. [5], Loginova I.O. [6], Kotova S.A. [7], Martishina M.V. [8], Fetisov A.S. [9], Rybakova N.A. [10] and others devoted their research to the problem of studying the personal characteristics of form masters.

Among the Russian social psychologists dealing with issues of socio-psychological climate in small groups, the following researchers can be mentioned: Kovalev A.G. [11], Karpov V.V. [12], Ershov A.A. [13], Kozlov A.S., Levina E.V. [14] and others.

A theoretical review of modern research has revealed the presence of synonymous terms describing the psychological climate: «emotional- psychological climate", "mental attitude", "psychological atmosphere", "socio-psychological situation" and others. According to modern psychology socio-psychological climate is the qualitative side of interpersonal relationships, which reveals itself as a community of psychological conditions that contribute to or hinder the diverse personal development and effective group activities. The psychological climate allows us to study an important component of interpersonal relationships, which determines the degree of emotional well-being of the class, it carries out joint activities, and it defines the level of comfort in the community of each student, and opportunities for the manifestation of personal "I" [15]. The relationship between the activity of each student and the influence of the community on him directly depends on the experience of emotional well-being of each child in his class.

There are two important functions of the psychological climate for the community: features of the individual's well-being in the community and stimulation of the productivity of joint activities [16].

It is worth remembering that the state of the psychological climate of the school team depends on the level of group development. Sufficient to say that a favorable psychological climate is positively correlated with high effectiveness of joint work. Successful group activity stimulates the development of mutual understanding and trust, sincerity and mutual help. Finally, it leads to the formation of a complete personality in each student, who will become an active unit in his team and at the same time the subject of his own life.

Positive, pro-social development of the individual becomes the effect of a favorable climate. An unfavorable climate, in turn, will slow down and hinder the social development of the individual. Any student can be ridiculed and humiliated in a classroom with an unfavorable climate. This will lead to the formation of increasing anxiety, low self-esteem, and a lack of security. Prolonged stay in the state of emotional distress leads to neurosis and didactogeny [17]. Certainly, students are in many ways responsible for the character of relations established in the group, but the role of the form master remains crucial in all circumstances. 
Scientists note that the existing atmosphere in the class is formed, first of all, by the form master. The peculiarities of interaction and mutual understanding with teenagers determine the specific results of school class activities that help to create the necessary psychological climate. It is proved that the direct influence on the psychological climate provides a group management style [18].

The ability to create a favorable psychological climate in a sponsored school class is considered by modern researchers as the form master's possession of the necessary professional competencies. This, in turn, leads to compliance with the requirements for the presence of certain personal qualities of the form master. These qualities include tolerance, communication skills, empathy, and organizational skills because he or she must be able to organize both joint activities of students, as well as their class activities and extracurricular activities with the supervised class. The presence of a favorable climate in the student classroom is evaluated as one of the important indicators of professional competence of a form master [19].

Among the factors that influence the psychological climate in the classroom of teenagers, the following are distinguished:

- $\quad$ high level of form master's competence (knowledge, methodological proficiency, reflection of personal experience, striving for professional self-development, ability to apply knowledge from pedagogy and psychology in practice);

- $\quad$ personal qualities (love for children, sincerity, sense of humor, desire to learn from teenagers, act as a mentor and friend for them, initiative, creativity, flexibility, sociability);

form master's acceptance of responsibility for the psychological climate in the supervised class [15].

The form master must understand that creating a conducive atmosphere for successful learning of students will lead to the emergence of high group cohesion, the class will become a reference group for each student.

\section{Materials and the results of the research}

In relation to the aforementioned, a study was organized and conducted in order to identify the features of the connections of personal qualities of the form master with the psychological climate in the school team.

The following research objectives were proposed:

- comparison of the psychological climate in school classes;

- $\quad$ diagnostics of personal traits of form masters;

- establishing the relationship between the personal characteristics of the form master and the psychological climate in the student classrooms using correlation analysis.

Empirical data were collected at the Vologda state secondary school № 42 in OctoberNovember 2019. 13-14-year-old students of 7th grades "A", "B", "C", "D", " E " (n=124 people) and 5 form masters who manage these classes made up the sample.

The following research methods were used: Cattell's Sixteen Personality Factor Questionnaire and psychological climate of the school team (V.S. Ivashkin, V.V. Onufrieva). We used Pearson correlation coefficient (Pearson's r) to determine correlations between the personal characteristics of the form master and the psychological climate in the school team.

A favorable psychological climate was identified in three classes, and an unfavorable one - in two classes according to the methodology of V. S. Ivashkin and V. V. Onufrieva. The results are shown in table 1. 
Table 1. Indicators of the psychological climate in school classes.

\begin{tabular}{|l|l|l|l|}
\hline Grade & $\begin{array}{l}\text { Average } \\
\text { indicator }\end{array}$ & Standard deviation & $\begin{array}{l}\text { The level of favorability } \\
\text { of the climate }\end{array}$ \\
\hline 7 " A " class & 5 & 0,5 & high \\
\hline 7" B " class & 5 & 0,6 & high \\
\hline 7" C " class & 2 & 0,07 & low \\
\hline 7" D " class & 5 & 0,2 & high \\
\hline 7"E " class & 2 & 0,06 & low \\
\hline
\end{tabular}

Positive relationships prevail in classes with a favorable psychological climate. All members of the class are friendly and they treat each other correctly. The also show tolerance and empathy for classmates and form masters. Interpersonal relationships are tense in classes with an unfavorable psychological climate. In such classes, students are not ready to help each other, they conflict with each other and form masters.

The data analysis that we received using Cattell's Sixteen Personality Factor Questionnaire helped us to pay attention to the dominant and lowest indicators on the scales. Grouping of data by personal traits of form masters was based on the degree of favorable psychological climate in the supervised classes. The data is presented in tables 2 and 3.

Table 2. Average values of form masters with a favorable psychological climate in supervised classes according to the Sixteen Personality Factor Questionnaire developed by Raymond B. Cattell.

\begin{tabular}{|l|l|l|}
\hline Scales & Sten & $\begin{array}{l}\text { Standard } \\
\text { deviation }\end{array}$ \\
\hline A & 8,5 & 1,8 \\
\hline B & 4,8 & 1,2 \\
\hline C & 9,7 & 1,5 \\
\hline E & 5,6 & 1,5 \\
\hline F & 5,2 & 1,4 \\
\hline G & 8,9 & 2,1 \\
\hline H & 8,8 & 1,4 \\
\hline I & 6,2 & 1,8 \\
\hline L & 4,5 & 1,7 \\
\hline M & 5,1 & 1,7 \\
\hline N & 6,2 & 2,7 \\
\hline O & 4,3 & 2,1 \\
\hline Q1 & 5,6 & 1,8 \\
\hline Q2 & 5,3 & 1,6 \\
\hline Q3 & 8,6 & 1,9 \\
\hline Q4 & 4,5 & 2,05 \\
\hline
\end{tabular}

Some factors were identified as the dominant factors for form masters with a favorable psychological climate in sponsored classes. Factor $\mathrm{C}$ (emotional instability and emotional balance), factor A (insularity - openness), factor $\mathrm{G}$ (dishonesty - fairness), factor $\mathrm{H}$ (timidity - courage), factor Q3 (impulsivity-control of desires) were identified. We can characterize these form masters as balanced, imperturbable, and capable of following social moral norms. They are good-natured, easy-going and open in communication. Such form masters are ready to cooperate, attentive to people, soft-hearted, kind, and able to adapt to communication partners. These masters prefer to work in a "Person-to-Person" situation, that has social significance, quickly and without stress are included in active groups, and are not afraid of criticism. They have social significance, they are included in active groups quickly and without any tension, they are not afraid of criticism. This group of masters has a good (professional) memory of events, first and last names and patronymics. They are 
distinguished by their demanding attitude, well-developed sense of duty, persistence, and ability to take responsibility, fairness, and wit. Such form masters demonstrate a tendency to emotional and activity-based self-control. They also show a tendency to be attentive to their communication partner regardless of their social status. They care about "self-respect" and concern for social reputation. Indicators of personality traits have an average level of severity for other factors.

These dominant features correspond to the ideal image of the form master. These are the requirements that the profession imposes on the professionally important qualities of form masters. That is, the identified personal traits of form masters with a favorable psychological climate in their supervised classes can be considered as professionally significant. Consequently, the identified personality traits of form masters with a favorable psychological climate in their supervised classes can be considered as professionally significant.

Table 3. Average values of form masters with an unfavorable psychological climate in supervised classes according to the Sixteen Personality Factor Questionnaire developed by Raymond B. Cattell.

\begin{tabular}{|l|l|l|}
\hline Scales & Sten & $\begin{array}{l}\text { Standard } \\
\text { deviation }\end{array}$ \\
\hline A & 6,9 & 1,2 \\
\hline B & 4,1 & 0,2 \\
\hline C & 3,2 & 0,05 \\
\hline E & 5,3 & 0,3 \\
\hline F & 7,8 & 0,9 \\
\hline G & 5,3 & 0,4 \\
\hline H & 6,2 & 0,3 \\
\hline I & 6,1 & 0,5 \\
\hline L & 7,2 & 0,06 \\
\hline M & 5,05 & 0,9 \\
\hline N & 5,14 & 0,2 \\
\hline O & 5,2 & 0,3 \\
\hline Q1 & 6,7 & 0,4 \\
\hline Q2 & 5,8 & 0,3 \\
\hline Q3 & 3,2 & 0,7 \\
\hline Q4 & 5,1 & 0,5 \\
\hline
\end{tabular}

The following is typical for form masters whose school teams have an unfavorable psychological climate (Details are given in table 3). The following factors were the dominant indicators: factor A (insularity - openness), F (concern - carelessness), L (trustfulness - suspiciousness). Therefore, these form masters are sociable, open, and aimed at establishing interpersonal contacts. In that way, a similar tendency was obtained for factor A with another group of form masters. However, such form masters are characterized by self-affirmation, self-confidence, independence of thought, propensity for asceticism, a desire to be guided by their own rules of behavior, hostility, authoritarianism, unwillingness to recognize authorities, and suspiciousness. Along with the dominant indicators, factors with low values were identified: factor $C$ (emotional instability - emotional balance) and factor Q3 (impulsivity - desire control). This group of form masters is characterized by a tendency to frustration, neurotic fatigue, irritability, low volitional self-control, inattention to communication partners, and the desire to avoid social requirements.

Thus, we can say that the personal characteristics of this group of form masters do not fit the requirements for the model of an acting specialist.

Further, we compared the personal characteristics of form masters and the peculiarities of the psychological climate in their supervised classes. The data is presented in table 4 . 
Table 4. Relationships between various indicators of the form master's personality traits and the level of psychological climate in the school team.

\begin{tabular}{|l|l|l|l|}
\hline Favorable psychological climate & \multicolumn{2}{|l|}{ Unfavorable psychological climate } \\
\hline 16 PF factors & $\begin{array}{l}\text { Significant } \\
\text { correlations }\end{array}$ & 16PF factors & $\begin{array}{l}\text { Significant } \\
\text { correlations }\end{array}$ \\
\hline A (openness) & at $\mathrm{p}<0.05$ & E (dominance) & at $\mathrm{p}<0.05$ \\
\hline C (emotional balance) & at $\mathrm{p}<0.05$ & $\begin{array}{l}\mathrm{C} \text { (emotional } \\
\text { instability) }\end{array}$ & at $\mathrm{p}<0.05$ \\
\hline Q2 (self-sufficiency) & at $\mathrm{p}<0.05$ & L (suspiciousness) & at $\mathrm{p}<0.05$ \\
\hline Q3 (desire control) & at $\mathrm{p}<0.05$ & - & - \\
\hline
\end{tabular}

As can be seen from table 4 , as a result of correlation analysis, 4 positive correlations were found between the indicator of a favorable psychological climate in supervised classes and the personality traits of form masters. A favorable psychological climate in the classroom positively correlates with the following personality traits of the form master: openness, emotional balance, self-sufficiency and desire control. Therefore, we can assume that these personality traits of the form master will help to maintain a favorable climate in the school teams.

3 positive correlations were found between the indicator of unfavorable psychological climate in the classroom and the personality traits of the form master. An unfavorable psychological climate in the classroom is positively associated with such personality traits of the form master as: dominance, emotional instability, suspiciousness. The presence of these personality traits is crucial for the formation of an unfavorable climate in the classroom of adolescents.

The study clearly showed us that teenagers continue to focus on the form master as a model of behavior that they copy, often unconsciously, in interpersonal relationships with classmates. It is not surprising, then, that teenagers demonstrate the features of communication that the form master offers them as a model in relation to each other in classes where an unfavorable psychological climate is revealed. Form masters need to remember that teenagers will quickly adopt and transfer the following negative aspects to their own model of communication with others: rudeness in communication, disrespect to the communication partner, insularity and inflexibility.

Unpleasant form masters' personal traits, especially their demonstration to other people, should be corrected with the help of training exercises and psychological consultation, both group and individual. It is important to advise the form master in such a way that after completing psychological counseling and a course of training exercises, he or she knows several points for the formation of a favorable psychological climate in the supervised class. He or she should:

1. know the age-dependent features of teenagers.

2. be able to take into account the individual characteristics of children, notice and regulate their emotional state.

3. use active listening techniques.

4. be able to react quickly and adequately in difficult situations for themselves and teenagers.

5. be able to create trusting relationships among teenagers in relation to themselves.

6. strive to praise each child even for minor successes continuously.

7. know the techniques of constructive criticism of their own behavior and the behavior of teenagers.

8. be able to regulate their own emotional state and the emotional state of teenagers.

9. show respect for every teenager [20].

According to the results of the study, it can be stated that the personal qualities of the form master significantly affect the characteristics of the management of the school team. 
The personality reveals itself in the content of its activity and in the ways and means of executing. The style of activity of the form master reveals his personal qualities, refracted to a certain extent through the characteristics and needs of the group of students led by him.

\section{Conclusions}

1. Communication with peers is crucial for the formation of a teenager's personality in adolescence. However, the teacher, namely the form master, remains an important agent of socialization for teenagers.

3 Such personality traits of the form master as openness, emotional balance, selfsufficiency and developed self-control are the basis of a favorable psychological climate in the classroom.

4 Such form master's personality traits as dominance, emotional instability, suspiciousness contribute to the establishment of an unfavorable psychological climate in the classroom of teenagers.

5 The importance of the psychological climate in the development of a teenager's personality shows the need for specially organized form master training, which will teach him to create and manage the psychological climate in the classroom.

6 Optimization of the psychological climate is an important reserve for improving the effectiveness of educational work in the classroom.

7 The ability of a form master to build relationships with students correctly is a confirmation of professional skills.

\section{References}

1. E.B. Petrushina, Socio-psychological features of interaction between the class teacher and students. Psychological science and education. Psychological and Pedagogical Research, 2 (5), 34-47 (2013)

2. V.N. Belkina, A.V. Kharkov, I.I. Revyakina, Theory and Practice of professional pedagogical reflection development: monography, p. 331 (Yaroslavl: Yaroslavl State Pedagogical University Publishing House, 2006)

3. A.S. Belkin, et. al., The personality of the teacher: the professional and personal characteristics and the demands of time: monography, p. 139 (Shadrinsk: Iset, 2004)

4. G.A. Praslova, Professional competence as a personal characteristic of a teachermusician. Art at school, 1, 70-72 (2007)

5. D.R. Merzlyakova, Syndrome of professional "burnout" and teacher's metaindividuality. Psychological Science and Education, 1, 55-61 (2009)

6. I.O. Loginova, Personal characteristics of teachers with different dynamics of life selffulfillment, Psychology of learning, 10, 91-112 (2010)

7. S.A. Kotova, Features of personal characteristics and life-meaning orientations of teachers with different work experience, Izvestia: Herzen University journal of humanities and sciences, 139, 25-34 (2011)

8. N.V. Martishina, Formation and development of a teacher's creative potential in the system of continuous pedagogical education: monography, 166 (Ryazan: Ryazan State University named for S. Yesenin, 2009)

9. A.S. Fetisov, Content characteristics of personal and professional qualities of the teacher as a component of the health-saving educational environment of the school. The Bulletin of the Voronezh State Technical University, 3-2 (10), 73-76 (2014) 
10. N.A. Rybakova, The personality of a modern teacher in a developing society, Psychology, sociology and pedagogy, 12 (63), 32-36 (2016).

11. A.G. Kovalev, Team and socio-psychological problems of management, p. 271 (Moscow, 2007)

12. V.V. Karpov, Leadership style in small groups and its relation to motivation and sociopsychological climate, Bulletin of the Saint Petersburg University of the Ministry of internal Affairs of Russia, 3, 230-234 (2008)

13. A.A. Yershov, Personality and team: Interpersonal conflicts in the team, their resolution, p. 175 (St. Petersburg, 2009)

14. A.S. Kozlov, E.V. Levina, A comprehensive method for making group decisions and assigning roles in a group. Values and meanings, 2 (18), 99-109 (2012)

15. I.V. Sablina, The role of the teacher in the formation of the psychological climate in primary schools. Concept, 11 (November), 66-70, access mode: http://ekoncept.ru/2013/13226.htm (2013)

16. R.S. Nemov, Socio-psychological analysis of the effective activity of the team, 2, 201 (Moscow, 2004).

17. I.E. Schwartz, Psychological climate as a pedagogical problem. Formation of the moral and psychological climate in the team, Interuniversity collection of scientific papers, 113 (Perm: Perm State Pedagogical Institute, 1985)

18. V.A. Averin, Personality psychology, 2, p. 189 (St. Petersburg: Mikhailov, 2001)

19. E.Yu. Guseva, K.M. Nikolaeva, The personality of the teacher and the psychological climate in the team. Scientific support of the professional development system, 1 (42), 58-70 (2020)

20. D.V. Savelyeva, Psychological counseling of teachers on the problem of creating a favorable psychological climate in the team of younger students, Science and education today, 10 (11), 105-106 (2016) 